\title{
Ultrasound diagnosis of unusual extratesticular mass: Case report and review of the literature
}

\author{
Lucio Dell'Atti \\ Urology Unit, Arcispedale "S. Anna", Ferrara, Italy.
}

\begin{abstract}
Гsummary
The adenomatoid tumor of the epididymis (EAT) is a neoplasm located in the paratesticular region. Mesothelial origin has been mentioned and inflammation has played some role in the development of these tumors. Physical examination and testicular ultrasound constituted important tools in the diagnosis. Some reports have mentioned malignant behavior, but it is very rare. Surgical treatment is the procedure of choice. We present the case of a 46-year-old patient with an adenomatoid tumour located in the head of the left epididymis that referred to our department with gradually enlarged intrascrotal mass.
\end{abstract}

KEY WORDS: Ultrasound; Extratesticular mass; Epididymis; Adenomatoid tumor.

\begin{abstract}
INTRODUCTION
Adenomatoid tumor is the most common epididymal tumor and accounts for approximately 30\% of all paratesticular neoplasms, second only to lipoma (1).

Adenomatoid tumors occur in men with a wide range of ages, with the majority being diagnosed in patients aged 20-50 years. Patients usually present with a painless scrotal mass. The tumors are round, well-circumscribed and can vary in size from a few millimetres up to $5 \mathrm{~cm}$. They are believed to be of mesothelial origin and are universally benign (2). Although more frequent in the tail, adenomatoid tumors may occur anywhere in the epididymis and have also been reported in the spermatic cord and tunica albuginea (3). On ultrasound (US) scans, they typically appear isoechoic and homogeneous mass. Because of the adenomatoid tumor's sonographic similary to malignant neoplasms, patients with these tumors usually undergo a surgical treatment.

In this case report is analyzed a case of adenomatoid tumor of the epididymis in a young-adult man.
\end{abstract}

\section{Case report}

A 46 years old man referred to our department for painless enlargement in the left hemiscrotum. Personal and familiar history were unremarkable, without epididymitis, torsion or trauma.

At physical examination colour changes and slight edema of the superior third of the scrotum were found, where it was observed a well defined, nodular, encapsulated tumor of $3 \times 3 \times 2 \mathrm{~cm}$ with firm consistency and related to the left epididymis, with which it formed a mass. No other relevant signs were found.

Ultrasonography confirmed a solid isoechoic lesion lying on the border between epididymal head and upper pole of the left testis without any disruption of the architecture of the testicular parenchyma (Figure 1). The testicular parenchyma immediately adjacent to the mass showed slightly decreased echogenicity compared with the parenchyma elsewhere. Preoperative laboratory investigation, including blood count and blood chemisties were within normal limits. Plasma levels of $\beta$-hCG ( $\beta$-subunit human chorionic gonadotropin), $\alpha$-fetoprotein (AFP), lactic dehydrogenase (LDH) were within normal ranges. The patient underwent surgical testicular exploration, which verified the existence of a nodular lesion in the upper pole of the left testicle meaduring $3 \times 3 \times 2 \mathrm{~cm}$, ovoid shaped, firm, limited and adherent to the testicle. Subsequently a tumorectomy was performed, with the 
Figure 1.

Longitudinal power-Doppler images of the scrotum shows an paratesticular mass, avascular, isoechoic with circumscribed aspect.

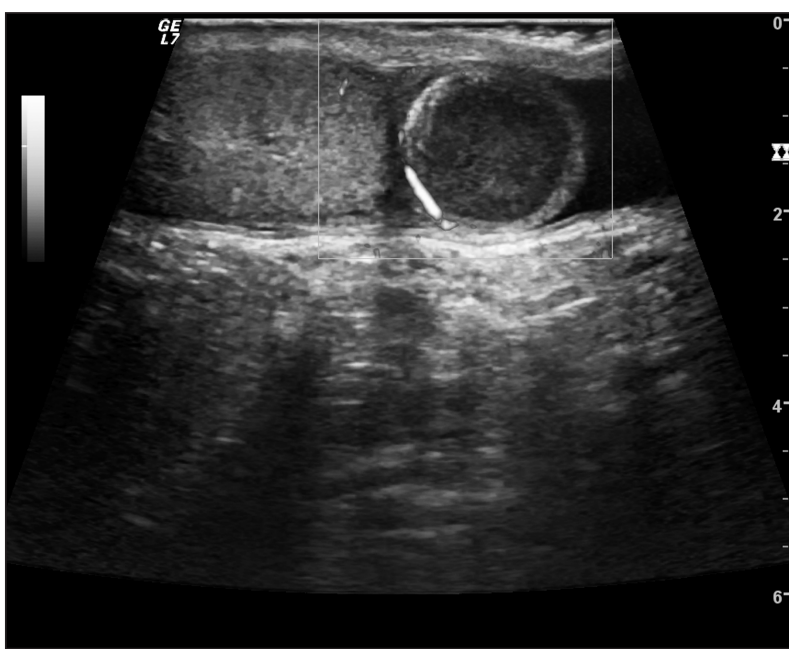

intraoperative histopathologic diagnosis of a benign lesion (Figure 2).

Histological appearance of this paratesticular tumor is represented by cuboidal cells, with vacuolated cytoplasm and with gaping spaces.

\section{Discussion}

Sakaguchi in 1963, described the first benign tumor of the epididymis, meanwhile Golden and Ash (4) in 1945, first used the EAT acronym, to indicate the most common paratesticular neoplasm. In 1976, Beccia et al. (5) gathered a total of 314 epididymal tumors, of which $75 \%$ were benign and of these $73 \%$ resulted to be EAT (55\% of the total), followed by leiomyomas (11\%) and by papillary cystadenomas (9\%). Angiomas, lipomas, and hamartomas constitute the remaining $7 \%$.

Gupta et al. (6) refer that primary malignant tumors of the epididymis constitute $25 \%$ of the tumors of this zone, although in geographical areas where still exists a high incidence of epididimary tuberculosis this incidence can fall below 1\% to constitute 3 groups: sarcomas, epithelial tumors and dysembrionary tumors. Although the EAT are considered by the majority of authors as benign, malignant forms of this tumor were also described (6-7).

A variety of neoplasms derived from mesenchymal elements may arise by the paratesticular tissues: carcinoma of rete testis, malignant mesothelioma, ovarian-type epithelial tumors, epididymidal carcinoma and metastatic carcinoma.

Most adenomatoid tumors of epididymis are asymptomatic and are found accidentally by the patient or by the physician during physical examination, as a non painful scrotal mass more commonly located at the tail of the epidydimis, which generally remains unchanged in size for years (8).
Figure 2.

Macroscopic findings on the surgical exploration. The testis appears normal. The tumor is connected to the head of the epididymis.

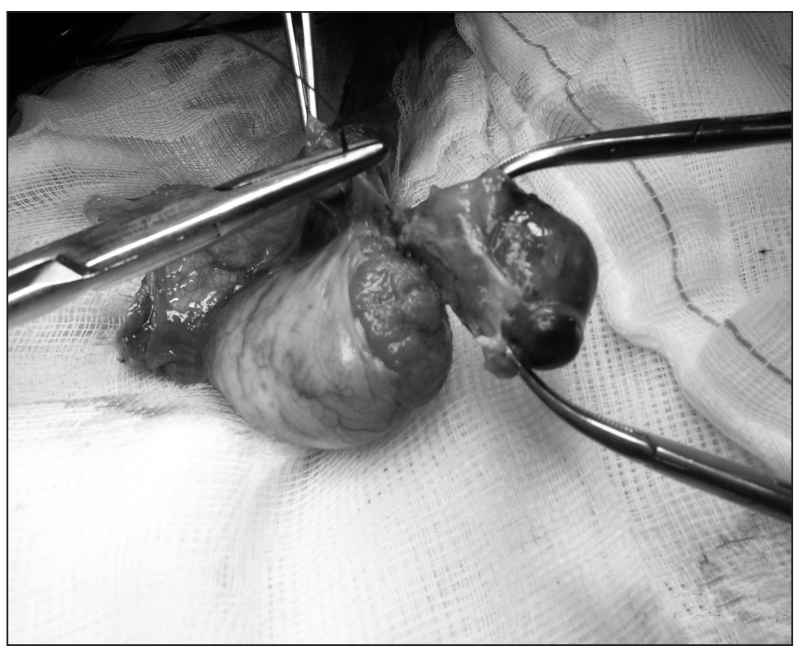

The possible histogenesis of adenomatoid tumors has aroused controversy and so far data are still contradictory.

However, the most recent investigations favour a mesothelial origin (9) although other pathologists considered it as a reaction to injury or inflammation. However, it is difficult to demonstrate such irritating factors in intrascrotal adenomatoid tumors.

\section{Conclusion}

US can be used to quickly and accurately estanilish whether an abnormal lesion is intratesticular or extratesticular. If it is extratesticular and cystic, a specific diagnosis can often be made (hydrocele, epididymal cyst, varicocele) and the patient can be reassured that the mass is benign.

Because of their sonographic features, the benign characteristics of solid extratesticular masses can be somewhat more problematic to diagnose by gray-scale and color flow Doppler sonography. Magnetic resonance imaging can be a problem-solving modality in some cases.

However extratesticular solid masses of uncertain diagnostic significance require surgical treatment as procedure of choice.

\section{References}

1. Benson CB, Doubilet PM, Richie JP. Sonography of the male genital tract. AJR Am J Roentgenol. 1989; 153:705-713.

2. Benign non-cystic scrotal tumors and pseudotumors. Acta Radiol. 2012; 53:102-111.

3. Kim TJ, Kim SH, Sim JS, Seong CK, Lee DK. Ultrasonographic findings of an intratesticular adenomatoid. J Ultrasound Med. 2000; 19:227-229. 
4. Golden A, Ash JE. Adenomatoid tumors of the genital tract. Am J Path. 1945; 21:63-79.

5. Beccia DJ, Krane RJ, Olsson CA. Clinical management of nontesticular intrascrotal tumors. J Urol. 1976; 116:476-479.

6. Gupta N, Rajwanshi A, Srinivasan R, Nijhawan R. Fine needle aspiration of epididymal nodules in Chandigarh, North India: an audit of 228 cases. Cytopathology. 2006; 17:195-8.
7. Bestard Vallejo JE, Tremps Velázquez E, Blázquez Mañá C, et al. Tumor adenomatoide de epidídimo: El tumor más frecuente de las estructuras paratesticulares. Actas Urol Esp. 2008; 32:611-7.

8. Fan K, Johnson DF. Adenomatoid tumor of ejaculatory duct. Urology. 1985; 25:653-4.

9. Delahunt B, Eble JN, Nacey JN, Thomton A. Immunohistochemical evidence for mesothelial origin of paratesticular adenomatoid tumour. Histopathology. 2001; 38:479.

\section{Correspondence}

U.O. Urologia, Azienda Ospedaliero-Universitaria Arcispedale "S. Anna" Via Aldo Moro 8 - 44124 Cona, Ferrara, Italy dellatti@hotmail.com 